\title{
Review
}

\section{Comparison of Guidelines on Non-Muscle Invasive Bladder Cancer (EAU, CUA, AUA, NCCN, NICE)}

\author{
Nicholas E. Power* and Jonathan Izawa \\ Department of Surgery \& Oncology, Divisions of Urology and Surgical Oncology, Western University, London, ON, \\ Canada
}

\begin{abstract}
.
Background: Non-muscle invasive bladder cancer (NMIBC) represents a considerably diverse patient group and the management of this complex disease is debatable. A number of panels from Europe and North America have convened on the topic and recently released guideline documents.

Objective: The purpose was to compare and contrast the NMIBC guideline recommendations from the EAU (Europe), CUA (Canada), NCCN (United States), AUA (United States), and NICE (United Kingdom).

Methods: All unabridged guideline documents were reviewed by the authors and comparisons were completed according to major topics in NMIBC.

Results: Despite a paucity of high level evidence regarding the majority of management topics in NMIBC, there was general agreement among the various guideline panels. Differences mainly centered on the categories of evidence synthesized and grades of recommendations. Each document offers a unique presentation of the available literature and guideline recommendation.

Conclusions: The guidelines for NMIBC from the EAU, CUA, AUA, NCCN, and NICE provide considerable consensus regarding the management of this often difficult disease. Clinicians are encouraged to familiarize themselves with all of the guidelines in order to determine which style of presentation would be most useful to their current practice.
\end{abstract}

Keywords: Guidelines, bladder cancer, review, Europe, Canada, United States

\section{INTRODUCTION}

A comparison of European and North American guidelines for the treatment of bladder cancer is a timely discussion topic as a number of groups have recently updated their documents as of 2015. This review concentrates on the current guidelines for nonmuscle-invasive (NMIBC) bladder cancer from the European Association of Urology (EAU), the American Urological Association (AUA), the Canadian

${ }^{*}$ Correspondence to: Nicholas E. Power, Department of Surgery, Urology Division, Western University, Victoria Campus, London Health Sciences, London, ON, N6A 5W9, Canada. Tel.: +1 519667 6787; E-mail: nicholas.power@lhsc.on.ca.
Urological Association (CUA), the National Comprehensive Cancer Network (NCCN), and the National Institute for Health and Care Excellence (NICE).

In order to produce a clinically useful tool, guideline panels must critically appraise current literature, discuss controversial areas where there is a lack of high level evidence, and synthesize a workable document that can aid patients and other clinicians in the field as to gold-standard treatment options. Most recommendations are based on lower level evidence wherein there is guideline panel consensus that an action is appropriate. For the purposes of comparison, it is interesting to note the differences in these expert opinions regarding patient management. The goal of this review is to 
highlight the differences in consensus recommendations among the groups to identify potential avenues for future collaborative clinical research.

\section{GUIDELINE PANELS AND HISTORY}

The EAU NMIBC guideline [1] panel consists of 11 members and 7 associate members. Most members of the guideline panel are urologists with the document stating a pathologist and biostatistician were included. The first EAU NMIBC guideline was published in 2000 with the latest 2015 edition being an update of the 2014 document. When the original guidelines were published in 2000, both NMIBC and muscle-invasive bladder cancer (MIBC) were combined, but subsequently were published separately for the first time in 2004 [3].

The CUA NMIBC guideline [3] panel consists of 13 members, all of whom are urologists. This 2015 iteration is the first updated and amended edition of the original 2007 CUA NMIBC guideline [4].

The AUA NMIBC guideline [5] panel consists of 8 urology members, 4 consultants, and 5 AUA staff. The original document was published in 1999 and reconstructed in 2007. This edition was updated and verified for validity in 2010 and in 2014, small amendments were made to reflect the additional availability of epirubicin and valrubicin in the United States.

The NCCN guideline [6] panel, that combines NMIBC and MIBC into one document, has 30 current members with 3 NCCN staff. There are 15 urologists, 8 medical oncologists, 2 hematologist/hematological oncologists, 3 radiation oncologists, 1 radiologist, and 1 pathologist. The original bladder cancer guideline publication was in 1998 [8]. All active NCCN guidelines are updated at least annually but interim panels edit the guidelines throughout the year based upon new evidence. The current NCCN bladder cancer guideline was last updated in May, 2015.

The NICE guideline panel consists of 15 members defined by the document as health professionals, lay representatives and technical experts known as the Guideline Development Group. Fourteen meetings were held from October 2012 to November 2014 in order to develop the guideline. Both NMIBC and MIBC are combined in one document.

\section{OVERALL GUIDELINE STRUCTURES}

The EAU guidelines for NMIBC contain a detailed discussion of bladder cancer from epidemiology
Table 1

Classification Schemes for Categorizing Evidence from Shekelle et al. [9]

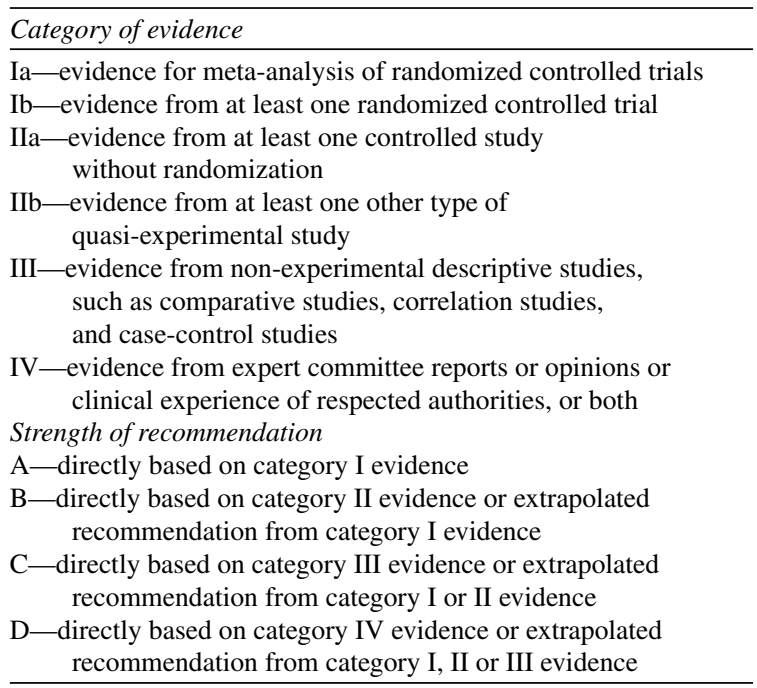

through treatment and follow-up. The guideline conclusions and recommendations are woven into the document after discussion subheadings along with the level of evidence (LE) and grade of recommendation (GR). The EAU employs the standard Oxford Centre for Evidence-Based Medicine 2011 Levels of Evidence (OCEBM) (http://www.cebm.net/wp-content/ uploads/2014/06/CEBM-Levels-of-Evidence-2.1.pdf) [9]. The GR are based upon the common strength of recommendation classification scheme espoused by Shekelle et al. (Table 1) [10] Treatment algorithms are part of the body of the document and are recapitulated, along with the major recommendations, in the "Pocket Guidelines" abridged version of the guideline. (http://uroweb.org/individual-guidelines/oncologyguidelines/)

The CUA NMIBC guideline takes a slightly different approach. It too uses OCEBM [9] but focuses more on controversial aspects of managing NMIBC as opposed to a complete review. There is a guideline statement with GR along with its corresponding LE followed by a discussion. One treatment algorithm is included. (http://www.cua.org/themes/web/assets/ files/nmibc_guideline_for_mem_rev_09_06_15.pdf)

The AUA NMIBC guideline is altogether different. This guideline completes a thorough discussion of NMIBC and offers suggested recommendations throughout the text, but only provides "treatment guideline statements" according to index patients. The panel first completed a review of the available literature concluding in 2006 and generated 
Table 2

NCCN Categories of Evidence and Consensus [6]

NCCN Categories of Evidence and Consensus

Category 1: Based upon high-level evidence, there is uniform NCCN consensus that the intervention is appropriate.

Category 2A: Based upon lower-level evidence, there is uniform NCCN consensus that the intervention is appropriate.

Category 2B: Based upon lower-level evidence, there is NCCN consensus that the intervention is appropriate.

Category 3: Based upon any level of evidence, there is major NCCN disagreement that the intervention is appropriate.

All recommendations are category $2 \mathrm{~A}$ unless otherwise noted.

meta-analyses using the "confidence profile statistical method", essentially a method to analyze data that are not from randomized controlled trials [11]. Outcome analysis identified specific treatment's efficacy (progression and recurrence) and complications. The guideline panel then generated treatment guideline statements and graded them according to "the degree of flexibility in their application." The 3 grades were "standard," "recommendation," and "option." "Standard" guideline statements had the least flexibility as a treatment whereas "option" had the most flexibility. These were defined by the AUA panel basically as consensus opinion and high level evidence as "standard," majority consensus and high level evidence as "recommendation," and equivocal consensus with low and/or insufficient levels of evidence as "option." Five index patients are then presented with graded treatment statements as indicated. (https://www. auanet.org/education/guidelines/bladder-cancer.cfm)

The NCCN guidelines are treatment algorithm based that use pathological stage and grade as the foundation and the flowchart expands from that point. The discussion following the algorithms is categorized mainly around treatment according to stage and grade of the bladder cancer. The 3 categories of evidence and consensus are combined and are defined by the NCCN as $1,2 \mathrm{a}, 2 \mathrm{~b}$, and 3 (Table 2). The levels of evidence follow loosely the OCEBM and combine with consensus grades $(1,2 \mathrm{a}$ unanimous, $2 \mathrm{~b}$ majority, and 3 disagreement). (http://www.nccn.org/ professionals/physician_gls/pdf/bladder.pdf)

The NICE bladder cancer guideline is the most extensive document of all reviewed. After guideline methodology is reviewed, algorithms are presented first. There are two pertaining to NMIBC: Diagnosis and Staging and Management of Non-Muscle-Invasive Bladder Cancer. The NICE guideline describes in great detail all aspects of bladder cancer from epidemiology through to managing locally advanced or metastatic bladder cancer. A list of key clinical issues are identified within scoping of the guideline and from this, the group then defined clinical questions. The clinical questions are explored through a review protocol (Table 3). "Evidence Profiles" were then critically appraised using the GRADE (Grading of Recommendations, Assessment, Development and Evaluation) Working Group strategy. (http://gradeworkinggroup.org/index.htm) This GRADE working group is a group of international experts who came together in the year 2000 as an informal collaboration of people with an interest in addressing the shortcomings of present grading systems in health care. The aim of the group was to develop a common, sensible approach to grading quality of evidence and strength of recommendation. The NICE guidelines grade the recommendations based on a simple overall quality of the evidence (high, moderate, low and very low) (Table 4). Another unique aspect of the NICE guideline is that it takes into consideration economic analysis and emphasizes patient-centered care in formulating the recommendations. The guideline

Table 3

Components of NICE guideline review protocol (from http://www. nice.org.uk/guidance/ng2)

\begin{tabular}{|c|c|}
\hline Component & Description \\
\hline Clinical question & $\begin{array}{l}\text { The clinical question as agreed by the } \\
\text { GDG }\end{array}$ \\
\hline Rationale & $\begin{array}{l}\text { An explanation of why the clinical } \\
\text { question is important. For example, } \\
\text { is the topic contentious? Is there } \\
\text { variation in practice across the } \\
\text { UK? }\end{array}$ \\
\hline $\begin{array}{l}\text { Criteria for considering } \\
\text { studies for the review }\end{array}$ & $\begin{array}{l}\text { Using the PICO (population, } \\
\text { intervention, comparison and } \\
\text { outcome) framework for questions } \\
\text { about treatment, or other suitable } \\
\text { framework for questions about } \\
\text { diagnosis or prognosis. Including } \\
\text { the study designs selected }\end{array}$ \\
\hline $\begin{array}{l}\text { How the information will } \\
\text { be searched }\end{array}$ & $\begin{array}{l}\text { The sources to be searched and any } \\
\text { limits that will be applied to the } \\
\text { search strategies; for example, } \\
\text { publication date, study design, } \\
\text { language. (Searches should not } \\
\text { necessarily be restricted to RCTs.) }\end{array}$ \\
\hline The review strategy & $\begin{array}{l}\text { The method that will be used to } \\
\text { review the evidence, outlining } \\
\text { exceptions and subgroups. Indicate } \\
\text { if meta-analysis will be used }\end{array}$ \\
\hline
\end{tabular}


Table 4

GRADE overall quality of outcome evidence (from http://www. nice.org.uk/guidance/ng2)

\begin{tabular}{ll}
\hline Quality element & Description \\
\hline High & $\begin{array}{l}\text { Further research is very unlikely to change } \\
\text { our confidence in the estimate of effect } \\
\text { Moderate }\end{array}$ \\
$\begin{array}{l}\text { Further research is likely to have an } \\
\text { important impact on our confidence in the } \\
\text { estimate of effect and may change the } \\
\text { estimate } \\
\text { Fow }\end{array}$ \\
$\begin{array}{l}\text { Further research is very likely to have an } \\
\text { important impact on our confidence in the } \\
\text { estimate of effect and is likely to change } \\
\text { the estimate }\end{array}$ \\
Any estimate of effect is very uncertain
\end{tabular}

is published online only. (http://www.nice.org.uk/ guidance/ng2)

\section{NON-MUSCLE-INVASIVE BLADDER CANCER GUIDELINES}

As evidenced by all five organizations having guidelines specific to NMIBC, in addition to the long-term survival and recurring nature of the disease, there exists considerable debate regarding the management of these patients. The following discussion will identify specific points where there is divergence of recommendations, but also, and importantly, identify areas where there is clear unanimity of opinion.

\section{INITIAL EVALUATION}

There is relative unanimity among the guidelines (except the CUA document that does not describe) regarding the initial evaluation of patients presenting with a suspicion of bladder cancer. A comprehensive history and directed physical exam followed by urine cytology, cystoscopy, and upper tract imaging is considered appropriate. The EAU NMIBC guideline recommends that a renal and bladder ultrasound (RBUS) should be performed with the initial hematuria workup (GR C) but once the diagnosis of NMIBC is made, CT urography (CTU) should be performed only in select cases (high risk tumors, multifocal, or located at the trigone) (GR B). The AUA, NICE and NCCN (category 2a) do not make such a distinction and recommend upper tract assessment with either CTU or RBUS/non-contrast CT combined with retrograde pyelogram, ureteroscopy, or MR urogram for all patients. The NICE guideline further recommends consideration of fluorodeoxyglucose positron emission tomography (FDG PET)-CT for people with high-risk NMIBC before radical treatment if there are indeterminate findings on CT or MRI.

In terms of obtaining a tissue diagnosis, a diagnostic transurethral resection of bladder tumor(s) (TURBT) and examination under anesthesia (EUA) is performed. All guidelines have recommendations regarding the performance of a TURBT but to varying degrees. The EAU has the most comprehensive guideline recommendations ranging from general principles of the technique to specific performance of the steps (GR B-C). The CUA panel considers complete excision of all visible tumors to include a depth down to muscularis propria as paramount (GR A). This is also considered a "standard" recommendation for the AUA and a principle of surgical management for the NCCN (category 2a). The NICE guidelines emphasize the requirement of obtaining detrusor muscle within the TURBT specimen and recommends repeat TUR within 6 weeks if none is identified initially.

\section{URINARY MOLECULAR MARKERS AND ENHANCED VISUALIZATION TECHNIQUES}

Due to the potential of missing the initial tumor or early recurrence, methods beyond white light cystoscopy (WLC) and urine cytology have been developed and are reviewed by the various guideline panels. In terms of molecular urinary markers, the EAU concludes that none of the currently developed tests meet the threshold to be included as a recommended strategy. Their conclusions state that various tests improve upon the sensitivity at the cost of lower specificity compared to cytology (LE 3) [12], benign conditions and BCG may influence results (LE 3), [13] test results depend on the clinical context of the patient (LE 3) [14], patient selection explains the wide range of performance of the tests, and UroVysion and microsatellite analysis can identify occult disease (LE 3) [15-18]. The CUA does not include recommendations regarding these tests whereas the AUA states that the tests may improve diagnosis and surveillance in NMIBC with no GR or LE. The NCCN panel states that consideration may be given to FDA-approved urinary markers, fluorescence in situ hybridization (FISH) or nuclear matrix protein 22 (NMP22) in monitoring for recurrence only (category 2a) [18, 19]. In terms of enhanced visualization techniques, the CUA NMIBC guideline panel reviews fluorescent (either with 5-aminolevulenic acid [5-ALA] and hexylaminolevulinate [HAL]) cystoscopy for photodynamic 
diagnosis (PDD) and narrow band imaging (NBI) utilization $[20,21]$. Although more practical using HAL, both 5-ALA and HAL PDD had similar efficacy in improving initial tumor detection and reduced recurrence (LE 1b) as well as NBI (LE 1b) [20]. The clinical impact on long-term recurrence and progression was unknown however. The EAU guidelines state that HAL PDD is more sensitive than conventional procedures at diagnosing malignant tumors (especially CIS) (LE 2a) but have lower specificity than WLC (LE 3) [22]. The beneficial value on recurrence rates was felt yet to be demonstrated conclusively however. In patients with positive cytology and no bladder tumor, the EAU recommends (GR B) PDD if available. Similarly, tumor detection rates improve with NBI (LE 3) but the results are not fully confirmed yet [23]. The AUA cites lack of specificity as the limiting factor in PDD's effective utility. The NCCN recommends judicious use of PDD possibly restricted to the detection of CIS, despite improved detection and reduced recurrence rates overall, due to the lack of evidence demonstrating prevention of progression and recurrence-free survival and the requirement of special expertise and equipment (category 2a). Contrary to the other guidelines, NICE recommends (Moderate to High quality) the use of WLC with one of PDD, NBI, cytology or a urinary biomarker test (such as UroVysion, ImmunoCyt NMP22 test) in patients with suspected bladder cancer. Interestingly, the increased initial costs of ancillary tests above urine cytology, were deemed by the group to be offset by more accurate diagnoses and decreased recurrences. The NICE guideline provides a much more favorable and comprehensive review of the evidence concerning PDD, $\mathrm{NBI}$ and the biomarker tests on initial evaluation. A strong caveat is emphasized however, that the urinary biomarker tests cannot replace cystoscopy for surveillance after bladder cancer treatment.

\section{REPEAT TURBT}

The value of repeat TURBT (within 2-6 weeks) due to the significant risk of residual tumor after initial TURBT [24], both for therapeutic and diagnostic reasons, are reviewed by all guidelines. The EAU recommends second TURBT (GR A) in select circumstances: incomplete resection, if no muscle is present in the initial resection (except CIS and low grade Ta), in all $\mathrm{T} 1$ tumors, and all high grade lesions (except primary CIS) $[25,26]$. The CUA recommends restaging TURBT be performed in cases of incomplete
TUR or T1 lesions without muscularis propria in the specimen (GR A) as well as all $\mathrm{T} 1$ or high-grade lesions regardless of muscularis propria within the specimen (GR C) [27]. The AUA provides a "standard" recommendation for repeat resection for all T1 lesions without muscularis propria in the specimen and all high-grade $\mathrm{T} 1 / \mathrm{Ta} / \mathrm{CIS}$ lesions that have recurred after prior intravesical therapy. The NCCN recommends a second TURBT be performed in all high-grade $\mathrm{Ta} / \mathrm{T} 1$ lesions after initial resection, especially in cases where no muscularis propria was detected (category 2a) [27]. The NICE document recommends (Low quality) repeat TURBT on all high-risk NMIBC patients within 6 weeks.

\section{PROSTATIC URETHRAL BIOPSY}

While the incidence of primary prostatic urethral involvement is low [28], secondary involvement often presents a diagnostic and therapeutic challenge. The CUA panel recommends biopsy of the prostatic urethra in patients with suspicious areas, extensive CIS, tumors at the bladder neck, and positive cytology without bladder tumor (LE 3) [29]. In conservatively managed patients, a TURP is recommended (GR B) prior to BCG with consideration of re-biopsy after induction (GR C) [30]. The EAU panel recommends (GR C) prostatic urethral biopsies in cases of suspicious areas within the area, bladder neck involvement, bladder CIS is present or suspected [31], and in cases of positive cytology without bladder tumor (GR B) [32]. CIS confined to the epithelial lining of the prostatic urethra can be treated using BCG with the addition of TURP (LE 3). The AUA makes no specific recommendations whereas the NCCN recommends (category 2a) prostatic urethral biopsy in sessile, high-grade, and/or CIS at the bladder neck. Tumors that are limited to the prostatic urethra with no acinar or stromal invasion, TURP and BCG is an appropriate management strategy (category 2a). The NICE guideline recommends that the status of the bladder neck and/or prostatic urethra should be factored in when considering intravesical therapy or radical cystectomy for high-risk NMIBC.

\section{RISK STRATIFICATION}

NMIBC exhibits a wide range of tumor biology and behavior. This heterogeneity is the reason why it is difficult to create treatment guidelines with numerous therapy options available. Risk stratification is one strategy to attempt to individualize a specific patient's 
treatment based on the risk of their tumor recurring and/or progressing. The NICE, EAU and the CUA incorporate this strategy into their guideline documents whereas the AUA and NCCN do not. The AUA and NCCN do however note that further refinement of individual risk is an area of active research and the AUA suggests that important risk adapted treatment can be implemented using the index patients presented in their NMIBC guideline. The EAU panel presents the most comprehensive review of the subject. The European Organization for Research and Treatment of Cancer (EORTC) Genito-Urinary Cancer Group (GUCG) has developed the most widely known stratification scheme [33] that uses individual patient data from 2,596 patients with Ta/T1 tumors randomized in seven clinical trials. Multivariate analysis identified number of tumors, tumor diameter, prior recurrence rate, stage, grade, and concomitant CIS as prognostic variables for disease recurrence and progression. Important caveats are that the majority received intravesical chemotherapy, did not undergo repeat TURBT, or receive maintenance therapy. Despite the limitations, the EAU recommends (GR B) stratifying patients into 3 risk groups (low, intermediate, and high; Table 5) defined according to the EORTC risk tables prior to a decision on disease management. The highest risk tumors are further defined using lower levels of evidence as those with the addition of concomitant prostatic urethral CIS and micropapillary variant histology (LE 3) [34]. In order to further aid in risk stratifi-

Table 5

EAU NMIBC guideline Risk Group Stratification [1]

\begin{tabular}{ll}
\hline Risk group stratification & Characteristics \\
\hline Low-risk tumours & Primary, solitary, Ta, G1* \\
& (PUNLMR LG), $<3 \mathrm{~cm}$, \\
& no CIS \\
Intermediate-risk tumours & All tumours not defined in \\
the two adjacent & categories (between the \\
& category of low- and \\
& high-risk) \\
& Any of the following: \\
& $\bullet$ T1 tumour \\
High-risk tumours & $\bullet$ G3** (HG) tumour \\
& $\bullet$ CIS \\
& Multiple and recurrent \\
& and large ( $>3 \mathrm{~cm}) \mathrm{Ta}$ \\
& G1G2 tumours (all \\
& conditions must be \\
& presented in this point)*
\end{tabular}

Substratification of high-risk tumours for clinical purposes can be seen in Table 7.2. * low grade is a mixture of G1 and G2. ** high grade is a mixture of some G2 and all G3 (see Fig. 4.1). CIS = carcinoma in situ; $\mathrm{HG}=$ high-grade; $\mathrm{LG}=$ low-grade. cation, the Club Urológico Español de Tratamiento Oncológico (CUETO) developed a similar model to the EORTC risk stratification based on 1,062 patients comparing various BCG treatment regimens [35]. Prognostic factors identified by CUETO include sex, age, prior recurrence status, number of tumors, stage, grade, and associated CIS. Again, important limitations noted were lack of second TURBT and no immediate postoperative instillation of chemotherapy used. The EAU recommends (GR B) using the CUETO risk stratification for those patients previously treated with BCG. The CUA panel agrees with the EORTC risk factors (LE 2a) yet also identify lymphovascular invasion (LVI), CIS of the prostatic urethra, and variant histology (LE 3) as other important variables to consider prior to a decision regarding treatment [35-37]. The NICE guideline recommends the use of EORTC prognostic factors yet relegates LVI and urothelial cancer variants to limited utility due to studies reviewed with small sample sizes with few patients with the factor under investigation. The group however does include aggressive variants (micropapillary and nested) in their consensus definitions of high-risk NMIBC.

\section{DISEASE MANAGEMENT}

\section{Intravesical treatment}

The AUA NMIBC guidelines state that there is no conclusive evidence that intravesical treatment reduces the rate of progression to muscle invasive disease. In addition, the optimal dose, number of doses or timing of doses for induction or maintenance therapy has yet to be clearly defined. For this reason, the AUA NMIBC panel found it difficult to compare or recommend specific regimens of intravesical treatment. Due to more evidence mounting in the field of intravesical therapy since 2006, the EAU, CUA, NICE and NCCN have more nuanced recommendations regarding its efficacy. By contrast, for example, the EAU NMIBC guidelines state that all patients with NMIBC should be considered for adjuvant therapy.

\section{SINGLE IMMEDIATE POST-OPERATIVE INTRAVESICAL CHEMOTHERAPY (T1/TA)}

The EAU recommends (GR A) one immediate (within 24 hours) chemotherapy instillation for patients with low or intermediate risk tumors. The panel based their recommendation on 3 large meta- 
analyses comprising 1,476 to 3,103 patients demonstrating reduced recurrence compared to TURBT alone (LE 1a) [38]. Further subgroup analysis suggested that the most benefit is derived from tumors with low recurrence rates (ie solitary, low grade Ta lesions). No comparisons have been made between mitomycin C, epirubicin, or doxorubicin and all appear effective (LE 1a) $[39,40]$. The CUA panel recommends (GR B) all patients with NMIBC should be considered for immediate postoperative instillation of chemotherapy. The guidelines suggest that the optimal timeframe is within 6 hours and significantly decreases after 24 hours (LE 2) [40]. Patients with deep/extensive resection or suspected bladder perforation should not receive this therapy (GR C) and for those in whom BCG is planned, the beneficial effect is less clear (GR D). The AUA identifies a single instillation of immediate postoperative chemotherapy a "recommendation" for the index patient of small volume, low grade Ta bladder cancer to prevent recurrence. The NCCN recommends observation with strong consideration of immediate postoperative intravesical chemotherapy (category 2a) only for Ta low grade tumors. The NICE guideline, however, recommends (Moderate to High quality) all patients with a suspected bladder cancer be given an immediate postoperative intravesicle dose of mitomycin $\mathrm{C}$.

\section{INDUCTION AND MAINTENANCE INTRAVESICAL THERAPY}

\section{Intravesical chemotherapy}

The EAU panel recommends (GR A) that all intermediate risk tumors be treated with induction chemotherapy (or BCG, see next section) followed by maintenance up to 1 year. The duration and intensity of the chemotherapy schedule remains undefined however (based on a systematic review [41]) but therapy longer than 1 year is not supported (LE 3). The CUA also recommends (GR B) induction chemotherapy followed by one year maintenance for intermediate risk tumors. The panel also recommends optimized mitomycin $\mathrm{C}$ administration (pre-treatment dehydration, urinary alkalinization, and higher concentrations) (GR B) [42]. The EAU panel recommends (GR B, LE 1b) optimization as well if using mitomycin $\mathrm{C}$. The AUA identifies index patient \#3 as a patient with multifocal and/or large volume Ta or a patient with recurrent low-grade Ta bladder cancer and categorizes induction mitomycin $\mathrm{C}$ as a "recommendation" and maintenance therapy to be an "option". The AUA panel cites cost, possible side effects, lack of accepted dosing schedule, and low risk of progression in the index patient as the reasons why there is less unanimity. The NCCN recommends induction intravesical chemotherapy in patients with low grade Ta similar to the AUA index patient \#3 (category 2a) [43, 44]. The NICE group recommends (range Very Low to High quality) all newly diagnosed intermediate-risk NMIBC patients undergo a course of at least 6 doses of intravesical mitomycin C. They based this on the relatively low risk of progression of intermediate-risk patients and the favorable toxicity profile of mitomycin $\mathrm{C}$ compared to $\mathrm{BCG}$. If the disease recurs after a course of intravesical mitomycin $\mathrm{C}$, the patient was recommended to be referred to a specialist urology multidisciplinary team.

\section{Intravesical BCG immunotherapy}

The EAU panel recommends intermediate risk patients be considered for either induction and maintenance chemotherapy (as above) or BCG (GR A) out to 1 year [45]. Although BCG may prevent or delay progression compared to chemotherapy [46, 47], the panel recommends this be weighed against the higher risk of side effects with BCG. In patients with high risk tumors however, the EAU panel recommends (GR A) full-dose intravesical BCG for 1-3 years (with years 2 and 3 benefit weighed against increased cost and inconvenience) [48]. A caveat is noted and the panel recommends that for patients at the highest risk of progression (GR C) and patients with BCG failure (GR $\mathrm{B})$ radical cystectomy is indicated. The CUA panel states that BCG induction with maintenance therapy is the standard of care for high-risk NMIBC (GR A). The panel also recommends (GR B) 3 years of maintenance in those who can tolerate it with dose reduction if significant intolerance. Induction and maintenance BCG may also be used in intermediate risk patients, although chemotherapy is favored by the panel (GR B). In these intermediate risk patients who fail chemotherapy, BCG may be given (GR B) or vice versa. The AUA considers induction and maintenance BCG a "recommendation" for index patient \#4 (those with high grade Ta, T1, or Tis). The NCCN panel recommends (category 2a) BCG induction and maintenance for intermediate and high risk NMIBC as well. They state that without further evidence, 3 years of maintenance remains the standard [49]. For those patients who are diagnosed with high-risk NMIBC, the NICE panel recommends (range Very Low to Moderate quality) a choice between intravesical BCG (induction and maintenance) or radical cystectomy. The upfront discussion 
of radical cystectomy was considered important due to uncertainty about the most effective primary therapy.

\section{Treatment of recurrences after $B C G$}

The EAU defines BCG failure into a number of categories. Progression to MIBC is the first. BCG refractory tumors (high grade NMIBC at 3 months [50]; CIS at both 3 and 6 months [51]; high grade tumor during therapy [52]) are considered failures. Any high grade tumor after initial response and after completing maintenance is also considered failure. Due to the unlikelihood of responding to further BCG, RC is the preferred option and treatments other than this should be considered oncologically inferior (LE 3) [53]. For patients designated as BCG refractory, the recommendation (GR B) is either RC or bladder-preserving strategies in patients unsuitable for cystectomy. For high-grade recurrence after BCG therapy, RC, repeat $\mathrm{BCG}$, or bladder preserving strategies are recommended (GR C). For non high-grade recurrences after BCG in primary intermediate tumors, repeat intravesical BCG/chemotherapy or $\mathrm{RC}$ is recommended (GR C). The CUA panel defines BCG failure as the presence of high grade NMIBC at 6 months from TURBT (or at 3 months if the initial tumor was high-grade T1) or any worsening of the disease while on therapy. In BCG refractory disease (defined as high grade NMIBC at 6 months or 3 months if the original tumor was high-grade $\mathrm{T} 1$; or progression in stage, grade or disease extent by 3 months after the first cycle of BCG), RC is recommended (GR B) [3]. In patients with $\mathrm{BCG}$ relapse (defined as recurrence of tumor after being disease free 6 months after therapy), BCG plus interferon [54], gemcitabine [55], or re-induction with BCG are valid options (LE 3) when patients are not suitable or refuse RC. The AUA panel's "recommendation" for index patient \#5 (high grade $\mathrm{Ta} / \mathrm{T} 1 /$ Tis after prior intravesical therapy) is that cystectomy should be considered. An "option" of further intravesical therapy may be considered. The NCCN panel recommends (category $2 \mathrm{a}$ ) that a second induction course of intravesical BCG or mitomycin $\mathrm{C}$ may be given in patients with recurrent tumors that responded initially. However, no more than 2 induction courses were recommended (category $2 \mathrm{a}$ ). If after the second course, the patient has Tis or Ta disease, the panel recommends (category $2 \mathrm{a}$ ) that switching to a different intravesical therapy is an option to cystectomy (valrubicin [56] or gemcitabine [57] are also mentioned). For patients with high-grade T1 disease after induction BCG, cystectomy is recommended (category 2a) although non-surgical candidates can consider other options. The NICE guideline recommends (Very Low to Moderate quality) all patients who fail induction course BCG to be considered for radical cystectomy. If the patient of clinical situation is unsuitable for radical cystectomy, further intravesical therapy may be considered, but there was considerable uncertainty regarding the optimal next steps.

\section{FOLLOW-UP}

While there is no high level evidence to support definitive recommendations on specific follow-up schedules, all guidelines suggest that cystoscopy with urine cytology should be completed at regular intervals based on the individual patient's risk. Interestingly, the NICE guideline does not recommend urinary biomarkers or cytology for follow-up of low-risk bladder cancer patients. Upper tract imaging every 1-2 years for patients with high risk NMIBC is also a unanimous recommendation.

\section{CONCLUSION}

The guidelines for NMIBC from the EAU, CUA, AUA, NCCN, and NICE provide considerable consensus regarding the management of this often difficult disease. There are, however, notable differences among the guidelines as well as extremely wide ranging presentations of their recommendations. Ultimately, the goal of guideline documents is to be a tool for the practicing clinician in order to optimize bladder cancer management. Clinicians, therefore, are encouraged to familiarize themselves with all of the presented guidelines in order to determine which style of presentation would be most useful to their current practice.

\section{REFERENCES}

[1] Babjuk M BA, Burger M, Compérat E, Kaasinen E, Palou J, Rouprêt M, van Rhijn BWG, Shariat S, Sylvester R, Zigeuner R. EAU Guidelines on Non-muscle-invasive Bladder Cancer (Ta, T1 and CIS) 2015. https://uroweb.org/guideline/nonmuscle-invasive-bladder-cancer/

[2] Witjes JA, Comperat E, Cowan NC, De Santis M, Gakis G, Lebret T, Ribal MJ, Van der Heijden AG, Sherif A. EAU Guidelines on Muscle-invasive and Metastatic Bladder Cancer 2015. https://uroweb.org/guideline/bladder-cancermuscle-invasive-and-metastatic/

[3] Kassouf W TS, Kulkarni GS, Breau RH, Zlotta A, Fairey A, So A, Lacombe L, Rendon R, Aprikian AG, Siemens DR, Izawa JI, Black P. CUA guidelines on the management of nonmuscle invasive bladder cancer. Can Urol Assoc J 2015;9(910):E690-E704 
[4] Kassouf W, Kamat AM, Zlotta A, Bochner BH, Moore R, So A, Izawa J, Rendon RA, Lacombe L, Aprikian AG. Canadian guidelines for treatment of non-muscle invasive bladder cancer: A focus on intravesical therapy. Can Urol Assoc J 2010;4(3):168-73.

[5] Hall MC CS, Dalbagni G, Pruthi RS, Schellhammer PF, Seigne JD, Skinner EC, Wolf JS. AUA Guideline for the Management of Nonmuscle Invasive Bladder Cancer: (Stages Ta,T1, and Tis): 2007 Update 2014.

[6] Clarke PE, SP, et al. NCCN Bladder Cancer Guideline 2015.

[7] Montie JE, Bahnson RR, Cohen SM, Drucker B, Eisenberger MA, El-Galley R, Herr HW, Hudes GR, Kuzel TM, Lange PH, et al. Bladder cancer. Clinical practice guidelines in oncology. J Natl Compr Canc Netw 2005;3(1):4-5, 19-34.

[8] Scher H, Bahnson R, Cohen S, Eisenberger M, Herr H, Kozlowski J, Lange P, Montie J, Pollack A, Raghaven D, et al. NCCN urothelial cancer practice guidelines. National Comprehensive Cancer Network. Oncology 1998;12(7A):225-71.

[9] Jeremy Howick IC, Paul Glasziou, Trish Greenhalgh, Carl Heneghan, Alessandro Liberati, Ivan Moschetti, Bob Phillips, Hazel Thornton. The Oxford 2011 Levels of Evidence 2011.

[10] Shekelle PG, Woolf SH, Eccles M, Grimshaw J. Clinical guidelines: Developing guidelines. BMJ 1999;318(7183): 593-6.

[11] Eddy DM, Hasselblad V, Shachter R. A Bayesian method for synthesizing evidence. The Confidence Profile Method. Int $\mathbf{J}$ Technol Assess Health Care 1990;6(1):31-55.

[12] van Rhijn BW, van der Poel HG, van der Kwast TH. Urine markers for bladder cancer surveillance: A systematic review. Eur Urol 2005;47(6):736-48.

[13] Lokeshwar VB, Habuchi T, Grossman HB, Murphy WM, Hautmann SH, Hemstreet GP, 3rd, Bono AV, Getzenberg RH, Goebell P, Schmitz-Drager BJ, et al. Bladder tumor markers beyond cytology: International Consensus Panel on bladder tumor markers. Urology 2005;66(6 Suppl 1):35-63.

[14] Vrooman OP, Witjes JA. Urinary markers in bladder cancer. Eur Urol 2008;53(5):909-16.

[15] Bergman J, Reznichek RC, Rajfer J. Surveillance of patients with bladder carcinoma using fluorescent in-situ hybridization on bladder washings. BJU Int 2008;101(1):26-9.

[16] van der Aa MN, Zwarthoff EC, Steyerberg EW, Boogaard MW, Nijsen Y, van der Keur KA, van Exsel AJ, Kirkels WJ, Bangma C, van der Kwast TH. Microsatellite analysis of voided-urine samples for surveillance of low-grade nonmuscle-invasive urothelial carcinoma: Feasibility and clinical utility in a prospective multicenter study (Cost-Effectiveness of Follow-Up of Urinary Bladder Cancer trial [CEFUB]). Eur Urol 2009;55(3):659-67.

[17] Roupret M, Hupertan V, Yates DR, Comperat E, Catto JW, Meuth M, Lackmichi A, Ricci S, Lacave R, Gattegno B, et al. A comparison of the performance of microsatellite and methylation urine analysis for predicting the recurrence of urothelial cell carcinoma, and definition of a set of markers by Bayesian network analysis. BJU Int 2008;101(11):1448-53.

[18] Grossman HB, Messing E, Soloway M, Tomera K, Katz G, Berger Y, Shen Y. Detection of bladder cancer using a pointof-care proteomic assay. JAMA 2005;293(7):810-6.

[19] Kamat AM, Dickstein RJ, Messetti F, Anderson R, Pretzsch SM, Gonzalez GN, Katz RL, Khanna A, Zaidi T, Wu X, et al. Use of fluorescence in situ hybridization to predict response to bacillus Calmette-Guerin therapy for bladder cancer: Results of a prospective trial. J Urol 2012;187(3):862-7.

[20] Burger M, Stief CG, Zaak D, Stenzl A, Wieland WF, Jocham $\mathrm{D}$, Otto W, Denzinger S. Hexaminolevulinate is equal to 5aminolevulinic acid concerning residual tumor and recurrence rate following photodynamic diagnostic assisted transurethral resection of bladder tumors. Urology 2009;74(6):1282-6.

[21] Naselli A, Introini C, Timossi L, Spina B, Fontana V, Pezzi R, Germinale F, Bertolotto F, Puppo P. A randomized prospective trial to assess the impact of transurethral resection in narrow band imaging modality on non-muscle-invasive bladder cancer recurrence. Eur Urol 2012;61(5):908-13.

[22] Kausch I, Sommerauer M, Montorsi F, Stenzl A, Jacqmin D, Jichlinski P, Jocham D, Ziegler A, Vonthein R. Photodynamic diagnosis in non-muscle-invasive bladder cancer: A systematic review and cumulative analysis of prospective studies. Eur Urol 2010;57(4):595-606.

[23] Cauberg EC, Kloen S, Visser M, de la Rosette JJ, Babjuk M, Soukup V, Pesl M, Duskova J, de Reijke TM. Narrow band imaging cystoscopy improves the detection of non-muscleinvasive bladder cancer. Urology 2010;76(3):658-63.

[24] Brausi M, Collette L, Kurth K, van der Meijden AP, Oosterlinck W, Witjes JA, Newling D, Bouffioux C, Sylvester RJ. Group EG-UTCC: Variability in the recurrence rate at first follow-up cystoscopy after TUR in stage Ta T1 transitional cell carcinoma of the bladder: A combined analysis of seven EORTC studies. Eur Urol 2002;41(5):523-31.

[25] Grimm MO, Steinhoff C, Simon X, Spiegelhalder P, Ackermann R, Vogeli TA. Effect of routine repeat transurethral resection for superficial bladder cancer: A long-term observational study. J Urol 2003;170(2 Pt 1):433-7.

[26] Divrik RT, Yildirim U, Zorlu F, Ozen H. The effect of repeat transurethral resection on recurrence and progression rates in patients with $\mathrm{T} 1$ tumors of the bladder who received intravesical mitomycin: A prospective, randomized clinical trial. J Urol 2006;175(5):1641-4.

[27] Herr HW. The value of a second transurethral resection in evaluating patients with bladder tumors. J Urol 1999;162(1):74-6.

[28] Kirkali Z, Canda AE. Superficial urothelial cancer in the prostatic urethra. Scientific World Journal 2006;6:2603-10.

[29] Kefer JC, Voelzke BB, Flanigan RC, Wojcik EM, Waters WB, Campbell SC. Risk assessment for occult malignancy in the prostate before radical cystectomy. Urology 2005; 66(6): $1251-5$.

[30] Orihuela E, Herr HW, Whitmore WF, Jr. Conservative treatment of superficial transitional cell carcinoma of prostatic urethra with intravesical BCG. Urology 1989;34(5):231-7.

[31] van der Meijden A, Oosterlinck W, Brausi M, Kurth KH, Sylvester R, de Balincourt C. Significance of bladder biopsies in Ta,T1 bladder tumors: A report from the EORTC GenitoUrinary Tract Cancer Cooperative Group. EORTC-GU Group Superficial Bladder Committee. Eur Urol 1999;35(4):267-71.

[32] Hara T, Takahashi M, Gondo T, Nagao K, Ohmi C, Sakano S, Naito K, Matsuyama H. Risk of concomitant carcinoma in situ determining biopsy candidates among primary non-muscleinvasive bladder cancer patients: Retrospective analysis of 173 Japanese cases. Int J Urol 2009;16(3):293-8.

[33] Sylvester RJ, van der Meijden AP, Oosterlinck W, Witjes JA, Bouffioux C, Denis L, Newling DW, Kurth K. Predicting recurrence and progression in individual patients with stage Ta T1 bladder cancer using EORTC risk tables: A combined analysis of 2596 patients from seven EORTC trials. Eur Urol 2006;49(3):466-5; discussion 475-467.

[34] Kamat AM, Gee JR, Dinney CP, Grossman HB, Swanson DA, Millikan RE, Detry MA, Robinson TL, Pisters LL. The case for early cystectomy in the treatment of nonmuscle invasive micropapillary bladder carcinoma. J Urol 2006;175(3 Pt 1):881-5.

[35] Fernandez-Gomez J, Solsona E, Unda M, Martinez-Pineiro L, Gonzalez M, Hernandez R, Madero R, Ojea A, Pertusa 
C, Rodriguez-Molina J, et al. Prognostic factors in patients with non-muscle-invasive bladder cancer treated with bacillus Calmette-Guerin: Multivariate analysis of data from four randomized CUETO trials. Eur Urol 2008;53(5):992-1001.

[36] Reading J, Hall RR, Parmar MK. The application of a prognostic factor analysis for Ta.T1 bladder cancer in routine urological practice. Br J Urol 1995;75(5):604-7.

[37] Millan-Rodriguez F, Chechile-Toniolo G, Salvador-Bayarri J, Palou J, Vicente-Rodriguez J. Multivariate analysis of the prognostic factors of primary superficial bladder cancer. J Urol 2000;163(1):73-8.

[38] Perlis N, Zlotta AR, Beyene J, Finelli A, Fleshner NE, Kulkarni GS. Immediate post-transurethral resection of bladder tumor intravesical chemotherapy prevents non-muscleinvasive bladder cancer recurrences: An updated metaanalysis on 2548 patients and quality-of-evidence review. Eur Urol 2013;64(3):421-30.

[39] Sylvester RJ, Oosterlinck W, van der Meijden AP. A single immediate postoperative instillation of chemotherapy decreases the risk of recurrence in patients with stage Ta T1 bladder cancer: A meta-analysis of published results of randomized clinical trials. J Urol 2004;171(6 Pt 1):2186-90, quiz 2435 .

[40] Kaasinen E, Rintala E, Hellstrom P, Viitanen J, Juusela H, Rajala P, Korhonen H, Liukkonen T, FinnBladder G. Factors explaining recurrence in patients undergoing chemoimmunotherapy regimens for frequently recurring superficial bladder carcinoma. Eur Urol 2002;42(2):167-74.

[41] Sylvester RJ, Oosterlinck W, Witjes JA. The schedule and duration of intravesical chemotherapy in patients with nonmuscle-invasive bladder cancer: A systematic review of the published results of randomized clinical trials. Eur Urol 2008;53(4):709-19.

[42] Au JL, Badalament RA, Wientjes MG, Young DC, Warner JA, Venema PL, Pollifrone DL, Harbrecht JD, Chin JL, Lerner SP, et al. Methods to improve efficacy of intravesical mitomycin C: Results of a randomized phase III trial. J Natl Cancer Inst 2001;93(8):597-604.

[43] Huncharek M, McGarry R, Kupelnick B. Impact of intravesical chemotherapy on recurrence rate of recurrent superficial transitional cell carcinoma of the bladder: Results of a metaanalysis. Anticancer Res 2001;21(1B):765-9.

[44] Huncharek M, Geschwind JF, Witherspoon B, McGarry R, Adcock D. Intravesical chemotherapy prophylaxis in primary superficial bladder cancer: A meta-analysis of 3703 patients from 11 randomized trials. J Clin Epidemiol 2000;53(7):67680.

[45] Malmstrom PU, Sylvester RJ, Crawford DE, Friedrich M, Krege S, Rintala E, Solsona E, Di Stasi SM, Witjes JA. An individual patient data meta-analysis of the long-term outcome of randomised studies comparing intravesical mitomycin $\mathrm{C}$ versus bacillus Calmette-Guerin for non-muscle-invasive bladder cancer. Eur Urol 2009;56(2): 247-56.
[46] Bohle A, Bock PR. Intravesical bacille Calmette-Guerin versus mitomycin $\mathrm{C}$ in superficial bladder cancer: Formal meta-analysis of comparative studies on tumor progression. Urology 2004;63(4):682-6; discussion 686-687.

[47] Sylvester RJ, van der MA, Lamm DL. Intravesical bacillus Calmette-Guerin reduces the risk of progression in patients with superficial bladder cancer: A meta-analysis of the published results of randomized clinical trials. J Urol 2002;168(5):1964-70.

[48] Zlotta AR, van Vooren JP, Huygen K, Drowart A, Decock M, Pirson M, Jurion F, Palfliet K, Denis O, Simon J, et al. What is the optimal regimen for BCG intravesical therapy? Are six weekly instillations necessary? Eur Urol 2000;37(4):470-7.

[49] Ehdaie B, Sylvester R, Herr HW. Maintenance bacillus Calmette-Guerin treatment of non-muscle-invasive bladder cancer: A critical evaluation of the evidence. Eur Urol 2013;64(4):579-85.

[50] Herr HW, Dalbagni G. Defining bacillus CalmetteGuerin refractory superficial bladder tumors. J Urol 2003; 169(5):1706-8.

[51] Sylvester RJ, van der Meijden A, Witjes JA, Jakse G, Nonomura N, Cheng C, Torres A, Watson R, Kurth KH. High-grade Ta urothelial carcinoma and carcinoma in situ of the bladder. Urology 2005;66(6 Suppl 1):90-107.

[52] van den Bosch S, Alfred Witjes J. Long-term cancer-specific survival in patients with high-risk, non-muscle-invasive bladder cancer and tumour progression: A systematic review. Eur Urol 2011;60(3):493-500.

[53] Lerner SP, Tangen CM, Sucharew H, Wood D, Crawford ED. Failure to achieve a complete response to induction BCG therapy is associated with increased risk of disease worsening and death in patients with high risk non-muscle invasive bladder cancer. Urol Oncol 2009;27(2):155-9.

[54] Joudi FN, Smith BJ, O'Donnell MA. National BCGIPIG: Final results from a national multicenter phase II trial of combination bacillus Calmette-Guerin plus interferon alpha-2B for reducing recurrence of superficial bladder cancer. Urol Oncol 2006;24(4):344-8.

[55] Dalbagni G, Russo P, Bochner B, Ben-Porat L, Sheinfeld J, Sogani P, Donat MS, Herr HW, Bajorin D. Phase II trial of intravesical gemcitabine in bacille Calmette-Guerinrefractory transitional cell carcinoma of the bladder. J Clin Oncol 2006;24(18):2729-34.

[56] Steinberg G, Bahnson R, Brosman S, Middleton R, Wajsman Z, Wehle M. Efficacy and safety of valrubicin for the treatment of Bacillus Calmette-Guerin refractory carcinoma in situ of the bladder. The Valrubicin Study Group. J Urol 2000;163(3):761-7.

[57] Skinner EC, Goldman B, Sakr WA, Petrylak DP, Lenz HJ, Lee CT, Wilson SS, Benson M, Lerner SP, Tangen CM et al. SWOG S0353: Phase II trial of intravesical gemcitabine in patients with nonmuscle invasive bladder cancer and recurrence after 2 prior courses of intravesical bacillus Calmette-Guerin. J Urol 2013;190(4):1200-4. 